\title{
Is there consistency between asymmetrical weight bearing in standing compare to sitting, in IS patients; and it's PT implementation?
}

\author{
Tamar Neuhous*, Lior Neuhaus Sulam \\ From 7th International Conference on Conservative Management of Spinal Deformities \\ Montreal, Canada. 20-22 May 2010
}

\section{Introduction}

The paper presents the results of weight distribution measurement, in sitting and standing positions, of the same idiopathic scoliosis patient who undergoes a conservative treatment. (Elaborated in results section.)

\section{Methods}

Subjects: 25 idiopathic scoliosis patients with the average age of 15.5 , various curves $\left(14^{\circ}-100^{\circ}\right.$ Cobb angle), undergoing physical therapy (Schroth method) for at least 3 months. $6 / 25$ subjects are using a brace. An asymmetry was calculated as \% of deviation from the expected $50 \%$ of weight bearing on each feet/ischium in unimpaired subjects. Healthy subjects weren't measured, since there're evidenced based proves to symmetrical weight distribution in sitting positions \& standing positions in healthy people.

\section{Materials}

"Fitrex" force plate - measurement pressure/sec. on each $\mathrm{cm}^{2}$; Sitting positions \& Standing positions.

6 measurement positions: "habitual" position, "self correction"/"brace correction", in Sitting positions \& Standing positions. 3 measurement of each position, each one lasted $30 \mathrm{sec}$, after each measurement the subjects stepped out of the plate.

\section{Results}

1. Is there a match, between idiopathic scoliosis type \& the side of the weight distribution, in Sitting positions \& Standing positions "habitual" position?

Modiin, Israel

Full list of author information is available at the end of the article
Weight distribution in a group of IS type rt. 4C, in both positions, was on the Tx concave side: in Sitting positions, $76.5 \%$ of the subjects \& in Standing positions, $64.7 \%$. While in groups, rt. $3 \mathrm{C} \&$ non3non $4,65 \%$ of subjects weight bearing was on the $\mathrm{Tx}$ convex side, in Standing positions \& no consistent results were detected in Sitting positions.

2. What is the quantitative influence of "self correction" / brace correction on weight distribution, in Sitting positions \& Standing positions?

The "self correction"/brace correction in both positions: respectively $56 \% / 66.66 \%$ of the subjects reduced the asymmetry \& even overcorrected.

3 . Is there a relation, between the side of the weight distribution, in Sitting positions \& Standing positions, "habitual" position \& "self correction"; "self correction" \& brace correction positions?

"habitual" position \& "self correction": $58.33 \%$ of the subjects demonstrated a similar weight distribution in both positions

"self correction" \& brace correction: $33.33 \%$ of the subjects were "corrected" more by the brace.

4. What is the size of weight bearing asymmetry between the positions?

In Sitting positions is twice larger than in Standing positions; $\mathrm{p}<0.0001$.

\section{Conclusions}

Sitting positions affixes the pelvis. Thus, spine alignment influences directly the pelvic weight distribution, while in Standing positions the distal structures are free, making the final weight distribution on feet be influenced by them. Group 4C demonstrated a consistency in Sitting positions, but not at Standing positions due to multiple degrees of freedom in Standing positions, as compared 
to Sitting positions. Group, 3C \& non3-non4, demonstrated the opposite tendency. This group result is to be taken carefully, as the sample is unrepresentative. Different weight distribution in both positions can be explained by: correctability \& flexibility of the curves; proprioceptive differences (feet/pelvis) \& body sway influence. Failure to achieve the symmetrical weight distribution can be explained by the poor physical ability (muscle endurance/range of motion) \& wrong proprioceptive input (of a true center). Those who improved the weight distribution symmetrical in one positions, didn't essentially succeed in other positions without sufficient specific training in those positions In general, the brace correction improved the symmetrical weight distribution. There is a need for specific training in brace, as an addition to the obvious advantages of bracing.

\section{Discussion}

The importance of specific training in each position (by established methods \& by using weight distribution measurement as biofeedback), in order to assimilate optimal weight distribution in ADL, was demonstrated, despite the small sample.

Published: 10 September 2010

doi:10.1186/1748-7161-5-S1-060

Cite this article as: Neuhous and Sulam: Is there consistency between asymmetrical weight bearing in standing compare to sitting, in IS patients; and it's PT implementation? Scoliosis 2010 5(Suppl 1):060.
Submit your next manuscript to BioMed Central and take full advantage of:

- Convenient online submission

- Thorough peer review

- No space constraints or color figure charges

- Immediate publication on acceptance

- Inclusion in PubMed, CAS, Scopus and Google Scholar

- Research which is freely available for redistribution

Submit your manuscript at www.biomedcentral.com/submit 